\title{
Éditorial
}

\section{7 janvier 2015}

Dévastés. C'est ce que beaucoup ont éprouvé ce jour là. Parce que les victimes nous avaient accompagnés pendant des années, parce qu'ils faisaient partie de nos vies, parce qu'ils nous avaient enseigné l'impertinence, le rire et la liberté. Parce qu'ils étaient les piliers d'une culture qui nous est chère. Comme si l'on avait assassiné ensemble Brassens, Brel et Ferré. Parce que nous avons ressenti cet acte barbare comme une injustice profonde, fusils contre crayons, brutalité contre innocence.

Au-delà des personnes, ce sont des principes qu'on a voulu détruire. Des principes auxquels la communauté universitaire est essentiellement attachée : la liberté de penser autrement, de critiquer, la confrontation des idées, le respect des différences. En tant qu'universitaires, en tant que chercheurs, nous avons à cœur d'avancer dans la voie de la connaissance, des idées neuves, dans le refus des dogmes et de la pensée fermée.

Nous sommes aussi des enseignants, et nous avons de ce fait une responsabilité forte dans la formation des acteurs de la société de demain. Surtout lorsque nous formons des enseignants et des éducateurs, qui seront eux-mêmes en charge de la jeunesse. Au-delà des savoirs scientifiques et des compétences professionnelles, derrière lesquels il est souvent confortable de se réfugier, l'université doit être porteuse de valeurs. On se pose beaucoup ces jours-ci la question de l'éducation à la citoyenneté dans les établissements scolaires. L'université n'est pas exonérée de cette responsabilité. D'aucuns pourrait considérer cette perspective comme une perte de temps, ou estimer qu'ils ne sont pas formés pour cela. La pédagogie universitaire est sans doute à réformer, et la formation citoyenne ne doit pas être occultée dans ce processus.

Didier Delignières

Éditeur Principal

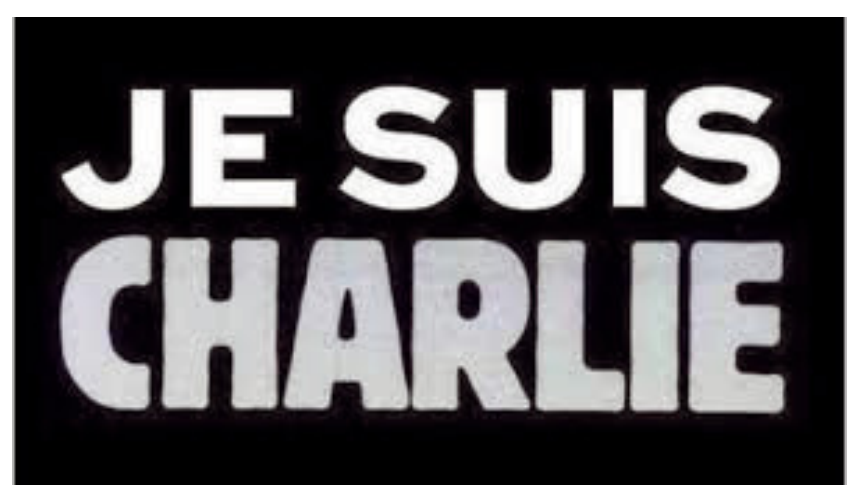

